\title{
Applications of Nuclear Techniques, Computer Simulation and Microscopy to Depth Profiling of Light Nuclei
}

\author{
J. Pacheco de Carvalho***, C. F. R. Pacheco** and A. D. Reis**** \\ * Departamento de Física, Universidade da Beira Interior, Covilhã, Portugal \\ ** Unidade de Detecção Remota, Universidade da Beira Interior, Rua Marquês d'Ávila e Bolama, \\ 6201-001 Covilhã, Portugal
}

There is a wide range of surface analysis techniques which are, generally, complementary and provide target information for depths near the surface. Nuclear techniques, which are non-destructive, provide for analysis over a few microns close to the surface giving absolute values of concentrations of isotopes and elements. They have been applied in areas such as scientific, technologic, industry, arts and medicine, using $\mathrm{MeV}$ ion beams [1-7]. Nuclear reactions permit tracing of isotopes with high sensitivities. We use ion-ion reactions and the energy analysis method. At a suitable energy of the incident ion beam, an energy spectrum is recorded of ions from the reaction, coming from several depths in the target. Such spectra are computationally predicted, giving target composition and concentration profile information [4-8]. Elastic scattering is a particular and important case. A computer program has been developed in this context, mainly for flat targets [4-7]. The non-flat target situation arises as an extension.

The method is successfully applied, mainly, to determination of: a very thin surface film of ${ }^{12} \mathrm{C}$ and ${ }^{16} \mathrm{O}$ concentration profiles in a thick flat silicon oxide target $(T 1)$ using $(\mathrm{d}, \mathrm{p})$ and $(\mathrm{d}, \alpha)$ deuteron induced reactions; ${ }^{12} \mathrm{C}$ concentration profiles in a thick flat target of pyrolitic graphite $(T 2)$. Resonant elastic scattering of $\left({ }^{4} \mathrm{He}\right)^{+}$ions is applied to depth profiling of $\mathrm{Al}$ and $\mathrm{O}$ in a thick flat aluminium oxide target (T3). Scanning electron microscopy is used as a very useful imaging technique to check target surface topography. In fitting simulated energy spectra to data, published nuclear data were used, such as our differential cross section data for the ${ }^{12} \mathrm{C}\left(\mathrm{d}, \mathrm{p}_{0}\right)^{13} \mathrm{C}$ reaction shown in Figure 1-A [5]. Some of the results obtained are illustrated in: Figure 1-B (SEM micrograph for T2); Figure 2-A for $T 1\left(\mathrm{E}_{\mathrm{d}}=1.0 \mathrm{MeV}\right.$ and $\left.135^{\circ}\right)$, using a uniform concentration profile of ${ }^{12} \mathrm{C}$ along $0.062 \mu \mathrm{m}$ and a uniform concentration profile of ${ }^{16} \mathrm{O}$ along $3.4 \mu \mathrm{m}$; and Figure 2-B for $T 3\left(\mathrm{E}_{\alpha}=3.105 \mathrm{MeV}\right.$ and $\left.165^{\circ}\right)$, using an $\mathrm{Al}$ uniform step concentration profile along $1.89 \mu \mathrm{m}$, a $\mathrm{O}$ uniform step concentration profile along $1.21 \mu \mathrm{m}$ and a ratio of atomic densities $\mathrm{C}_{\mathrm{O}} / \mathrm{C}_{\mathrm{Al}}=1.500$. The combined use of nuclear techniques and SEM microscopy has shown to be highly important for surface analysis of materials. The mentioned results would be very difficult to obtain by other techniques.

\section{References}

1. J.R. Tesmer, M. Nastasi (Eds.), Handbook of Modern Ion Beam Materials Analysis, Materials Research Society, Pittsburgh, PA, 1995

2. G. Amsel, G. Battistig, Nucl. Instr. and Meth. B 240 1, 2005

3. J.M. Calvert, D.J. Derry, D.G. Lees, J. Phys. D: Appl. Phys. 7: 940, 1974

4. J.A.R. Pacheco de Carvalho, Ph. D. Thesis, University of Manchester, England, 1984

5. J.A.R. Pacheco de Carvalho, A.D. Reis, Nucl. Instr. and Meth. B 266, 10: 2263, 2008

6. J.A.R. Pacheco de Carvalho, A.D. Reis, Bol. Soc. Esp. Ceram. V. 47, 4: 252, 2008

7. J.A.R. Pacheco de Carvalho, C.F.F.P.R. Pacheco, A.D. Reis, Adv. Mat. Res. V. 107: 123, 2010

8. N.P. Barradas et al., Nucl. Instr. and Meth. B 262: 282, 2007 

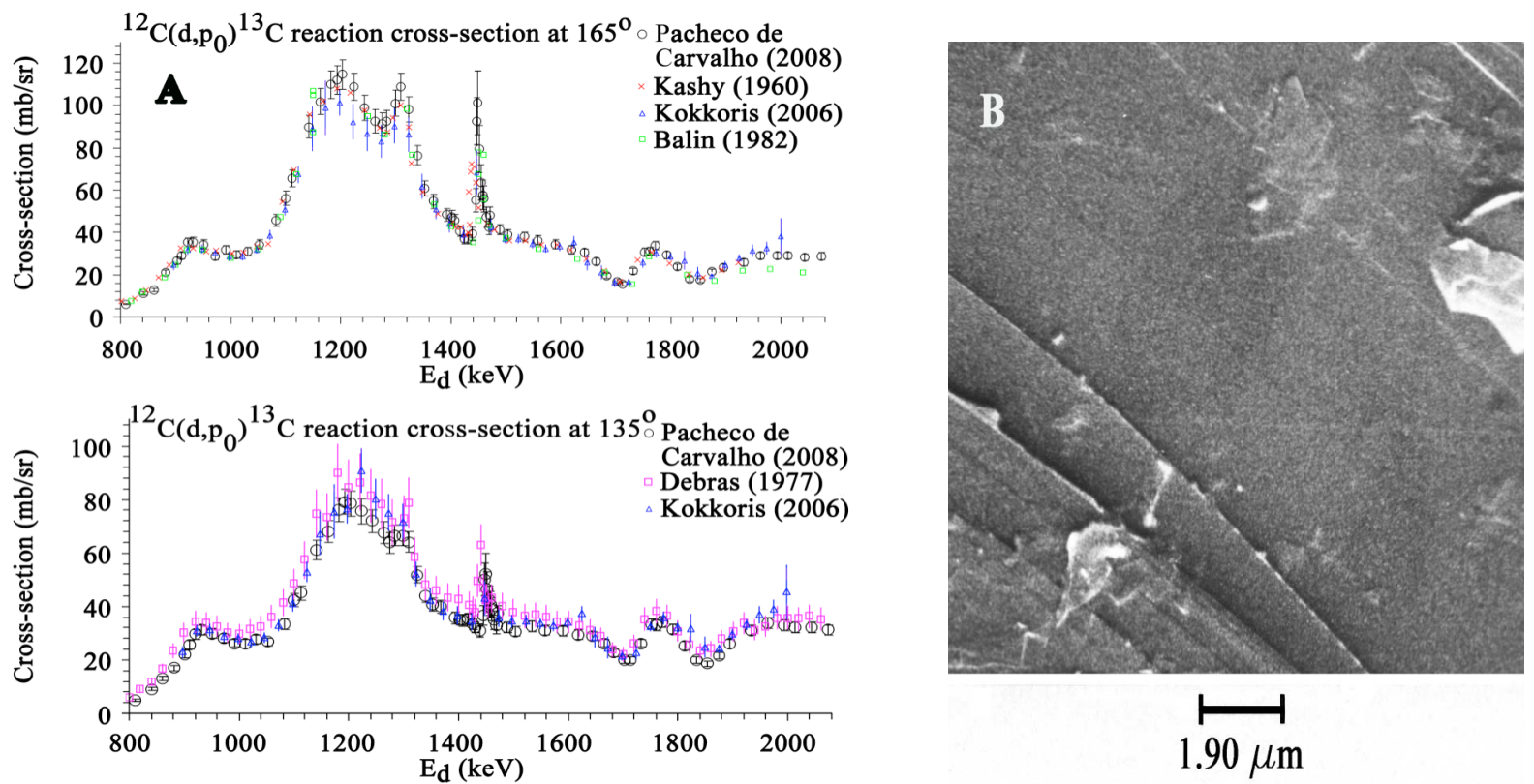

Figure 1. Differential cross-section data and SEM micrograph. A. Comparison of measured values of the differential cross-section for the $12 \mathrm{C}(\mathrm{d}, \mathrm{p} 0) 13 \mathrm{C}$ reaction for $\mathrm{Ed}=810-2073 \mathrm{keV}$ at $165^{\circ}$ and $135 \mathrm{o}$ with other published data [5]. B. SEM micrograph of target T2.
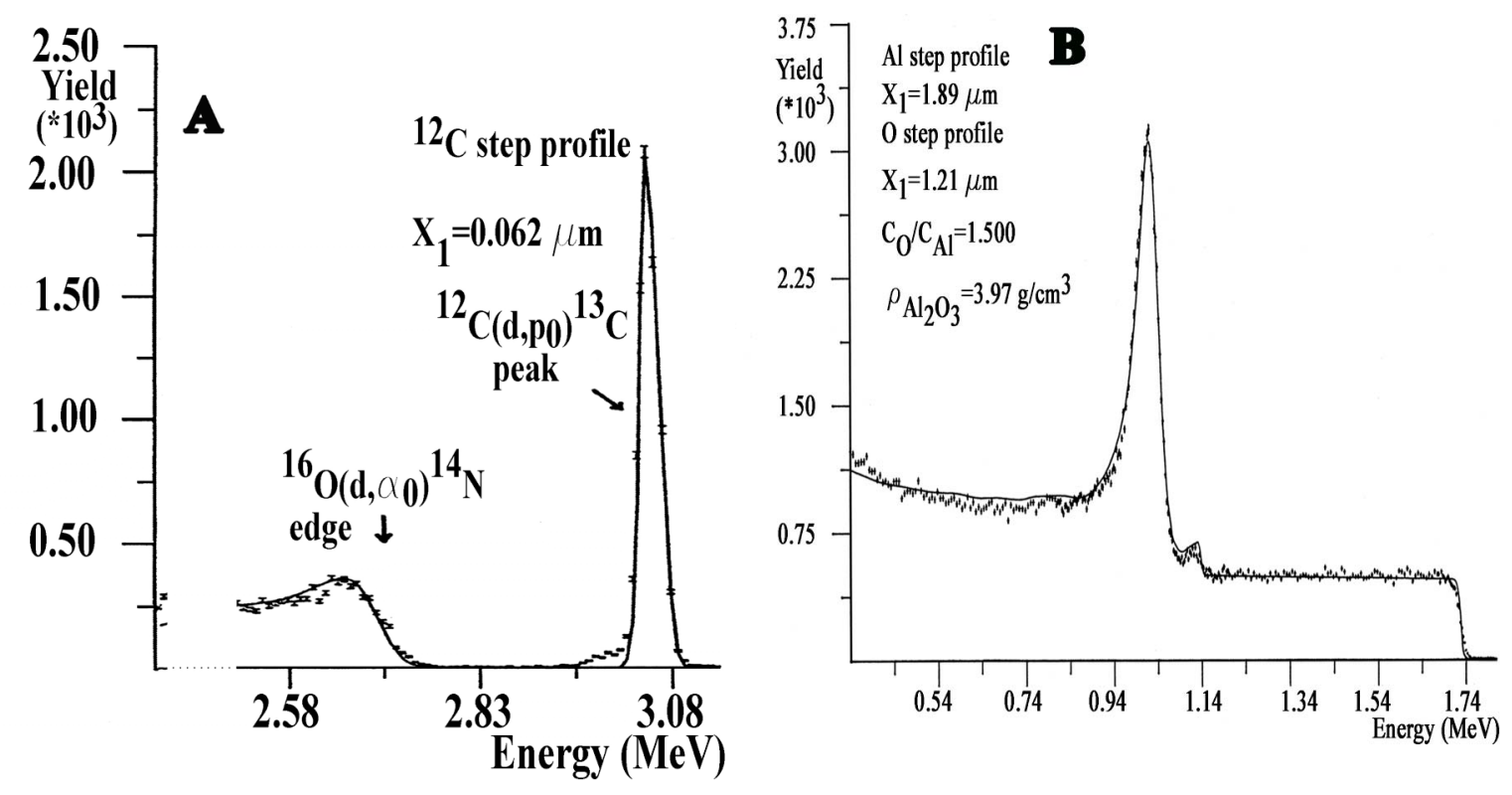

Figure 2. Computed fits to energy spectra. A. Details of the computed fit for $(d, p)$ and $(d, \alpha)$ reactions in target $\mathrm{T} 1, \mathrm{Ed}=1.0 \mathrm{MeV}$ and $135 \mathrm{o}$. B. Computed fit to data of elastic scattering of $\alpha$ particles in target $\mathrm{T} 3$ for $\mathrm{E} \alpha=3.105 \mathrm{MeV}$ and $165^{\circ}$. 